This is the Accepted Version of the below article which will be published by Edinburgh University press in Word Structure: http://www.euppublishing.com/loi/word

Accepted Version originally downloaded from SOAS Research Online: http://eprints.soas.ac.uk/22329/

\title{
Denominal adjectives as mixed categories
}

Andrew Spencer, University of Essex and Irina Nikolaeva, School of Oriental and African Studies, University of London

\begin{abstract}
Many languages have morphological devices to turn a noun into an adjective. Often this morphology is genuinely derivational in that it adds semantic content such as 'similar-to- $N$ ' (similitudinal), 'located-on/in' (locational) and so on. In other cases the denominal adjective expresses no more than a pragmatically determined relationship, as in preposition-al phrase (cf. the synonymous preposition phrase), often called 'relational adjectives'. In many languages relational adjectives are noun-to-adjective transpositions, that is, adjectival forms ('representations') of nominals. In some languages and constructions they retain some of the noun-related properties of the base. For example, the base can be modified by an attribute as though it were still a syntactically represented noun, giving rise to what we will call 'syntagmatic category mixing'. We also find instances of 'paradigmatic category mixing' in which the derived adjectival form retains some of the inflectional morphology (case and/or number and/or possessive) of its base noun, as in a number of Uralic and Altaic languages. We address this kind of categorial mixing within the descriptive framework for lexical relatedness proposed in Spencer (2013). A true transposition has a complex 'semantic function' (sf) role, consisting of the semantic function role of the derived category overlaid over that of the base. We explain how the complex semantic structure role of noun-to-adjective transpositions maps onto cstructure nodes, using the syntactic framework of Lexical Functional Grammar.
\end{abstract}

Keywords: denominal adjective, mixed category, transposition, semantic function role, Lexical Functional Grammar

\section{Introduction}


The concept of 'mixed category' is familiar from the study of action nominalizations (Comrie and Thompson 2007; Schachter and Shopen 2007; Alexiadou 2010a, b). ${ }^{1}$ There we find a word which has many of the outward properties of a noun, but which retains some of the properties of its verb base, such as licensing arguments and being modifiable by VP-oriented adverbials. For instance, the form destroying in The Government's/their systematically destroying all the evidence (appalled us) has a possessive form specifier The Government's/their like a noun but is modified by an adverb systematically and takes a direct object all the evidence. The semantics of the action nominal is not significantly different from that of the base verb, and there is a sense in which a word form such as destroying is best thought of as a form of the lexeme DESTROY rather than a distinct lexeme in its own right. Such mixed categories are therefore intermediate between canonical inflection and canonical derivation.

We will refer to the syntactically mixed behaviour of the kind shown above by destroying as 'syntagmatic mixing'. In languages with rich inflectional morphology such categories usually belong to the inflectional paradigm of the derived category while preserving some morphological properties of the base category. For instance, deverbal participles in inflecting Indo-European languages generally inflect as adjectives but often inflect for voice, aspect or even tense categories, just like verbs (cf. Lowe 2015 on Sanskrit). We will call this latter type 'paradigmatic mixing'.

Categorial mixing is not limited to deverbal nouns and participles. Cross-linguistically these properties can also be found with the other types of mixed category. Each of the three major lexical categories, noun, verb, adjective, can logically give rise to two such mixed categories, giving a total of six different types of mixed category (Spencer 2005, 2013): verbs give nominals and adjectivals (participles), adjectives give predicative forms (is-tall) and nominals (property nominalizations, tallness), and nouns give predicative forms (is-a-doctor) and adjectivals, in particular, the relational adjectives (RAs), a subtype of denominal adjective (DA), the topic of this chapter.

Before we illustrate categorial mixing in RAs, we will introduce some general notions important for our argument in Section 2. A key feature of the syntagmatic categorial mixing shown by RAs is the fact that the base noun of the derived adjective seems to 
remain syntactically 'visible' for attributive modification, what we will call 'attributive transparency'. This, together with violations of anaphoric islandhood, constitutes a violation of a subtype of lexical integrity which we will call 'lexemic integrity'. We argue that such violations are characteristic of transpositions, a notion we further explicate in that section. In Section 3 we argue that cross-linguistically many (though not all) instances of RAs are true transpositions which exhibit paradigmatic and/or syntagmatic category mixing. Since transpositions change morpholexical category without creating a new lexeme, they pose a problem for most models of morphology.

In Section 4 we discuss these issues within the descriptive framework for lexical relatedness proposed in Spencer (2013). This model is not committed to an inflection/derivation distinction, but rather factorizes relatedness so that (canonical) inflection and (canonical) derivation represent poles of a whole series of types of relatedness. A key motivation for this model is the existence of transpositions. We will situate the mixed category DAs in that model and then discuss how canonical transpositional RAs differ from what Spencer (2013) refers to as 'transpositional lexemes'. We will show that we can only successfully distinguish true transpositions from transpositional lexemes by appeal to the notion 'lexeme' as individuated formally by means of a unique lexemic index. In Section 5 we discuss how noun-to-adjective transpositions may be represented in syntax using the framework of Lexical Functional Grammar or LFG (Dalrymple 2001) and sketch the semantics of the construction. Section 6 offers general conclusions and suggestions for future research.

\section{Lexemic integrity and transpositions}

A characteristic of lexicalist approaches to grammar of the sort we assume is a distinction between words and phrases. The structure and distribution of phrases is the concern of syntax while the structure and distribution of words is the concern of morphology. These two domains of grammar are autonomous in the sense that syntactic processes do not have direct access to the internal structure of words. This is (one aspect of) the property of lexical integrity. 
In this section we explore one specific aspect of lexical integrity, which we will refer to as 'lexemic integrity'. By this we mean that a single lexeme, even if it is a morphologically complex word will always have the same syntactic distribution as a morphologically simplex member of the same category (cf. the Atom Condition of Williams 1981a). Thus, all syntactic processes should treat a derived adjectival lexeme such as friendless on a par with a morphologically simplex lexeme such as sad.

There are various ways in which the strictest interpretation of lexical or lexemic integrity is too strong. Some lexemes are multiword expressions, that is, they consist of other lexemes (for instance, light verb constructions), and some inflected word forms are multiword expressions (periphrastic inflection). These are not relevant to our argument so we leave them aside. We will focus on expressions which apparently are single words in the sense of being single syntactic terminals, but which nonetheless appear to belong to two different lexical categories, and thus violate what we will call 'lexemic integrity'. The two properties that we focus on in this paper are anaphoric islandhood and what we will call 'attributive transparency/opacity'.

Postal (1969) raised the question of whether parts of words can serve as the targets of anaphoric or cataphoric reference (outbound anaphora). He concluded that an anaphoric relation between, say, a nominal base in a derived word and a pronoun was impossible, that is, a word is an anaphoric island. Thus, it is (allegedly) ungrammatical to say *He's a famous [guitar]ist and he paid a lot of money for $i t_{i}$, in which the pronoun it is intended to be in an anaphoric relation to the base, guitar, of guitarist.

Anaphoric islandhood is generally taken to correlate with other indications of lexical integrity. For instance, a lexicalized compound such as teapot appears to consist of the words tea and pot, but this is misleading: the word tea is not syntactically or semantically active in the compound teapot. It is not syntactically active in the sense that it cannot be modified by an attribute external to the compound. Nor is it possible to coordinate tea with another noun: an expression such as [a [tea-or-coffee] pot] has the flavour of a linguistic joke rather than a genuine grammatical output. The head of the compound cannot be separated from the compound itself in a phoric construction, either. Whereas we can say Let's buy the green teapot rather than the blue one, where 
'one' substitutes for the noun teapot, it is not possible to say Let's buy a teapot rather than a coffee one as an alternative to Let's buy a teapot rather than a coffeepot. Finally, teapot is an anaphoric island: it is not possible to refer to tea with a pronominal of any kind. For instance, unless tea has been mentioned in prior discourse it is not possible to say Here's the tea $a_{i}$ ot but someone's already drunk all of it.

Nonetheless, there are instances in which it appears that proper parts of a word can be targeted by anaphoric relations and this led Ward et al. (1991) to argue that words are not (necessarily) anaphoric islands, but that the determinants of the violations are essentially pragmatic. We will deploy the property of outbound anaphora conservatively, therefore: if outbound anaphoric reference is completely excluded in all types of discourse we will take this as evidence that we are dealing with a single word/lexeme. However, if outbound anaphoric reference is possible, we cannot (necessarily) take this to mean that we are definitely dealing with more than one word; rather, we take it as weak evidence in favour of a lexemic integrity violation.

The second property we consider, attributive transparency, is the one that will be the main focus of our discussion. It ensures that the individual parts of morphologically complex words do not serve as independent phrasal heads. One of the entailments of this principle is that the base noun of a DA will not be accessible for attributive modification. This is true of friendless: we cannot form *trusted friendless (intended meaning 'without a trusted friend') from trusted friend. We will say that adjectives like friendless are unable to license 'inbound attributive modification'.

One particular case where lexemic integrity appears to be violated is that of transpositions, derived words which differ from their bases in morphological and syntactic category, but which have the same lexical meaning. ${ }^{2}$ A transposition typically acquires the 'external' morphosyntax of the derived class while retaining some of the 'internal' morphosyntax of the base class (see Haspelmath 1996 for the terms 'external/internal' in this context). Thus, a participle is externally an adjective which retains certain verbal properties while a relational adjective is externally an adjective which retains certain nominal properties. 
Booij (1996) introduces a useful informal distinction between contextual and inherent inflection. Contextual inflection is purely formal, such as agreement morphology, lacking any semantic contribution of its own. Inherent inflection is inflection for morphosyntactic properties which are inherent to that word class. Such inflection often seems to introduce meaning contrasts. For instance, spatial case markers introduce locational predicates of various sorts such as 'IN' or 'FROM THE SURFACE OF'. The canonical transpositions resemble contextual inflection in that they fail to enrich the semantic content of the base lexeme. For instance, the participial form writing can be used as an attributive modifier, as in the girl [writing the letter]. Such a form has exactly the same lexical meaning as inflected forms e.g. writes, wrote, or indeed writing in the girl (who) is writing the letter. This is equally true in languages in which participles inflect like adjectives and agree with their head nouns in properties such as gender, number, case, such as Russian: pišuščaja pis'mo devuška (writing.F.NOM.SG letter girl[F].NOM.SG). As such, canonical transpositions have to be regarded as members of the base lexeme's paradigm rather than a distinct lexeme in their own right, though without being proper inflected forms.

However, Spencer (2013) further argues that just as inherent inflection can be meaningbearing so some transpositions can be associated with additional semantic content. Such transpositions are less canonical and Spencer refers to them as 'meaning-bearing transpositions'. One example he discusses is the German -ung nominals, which on the one hand, behave like transpositions but, on the other hand, add extra (aspectual) meaning to the original verb and arguably do not (necessarily) create a new lexeme. ${ }^{3}$ We will see similar examples of DAs in our discussion of Selkup in Section 4.

We will demonstrate in the next section that the transpositional DAs exhibit syntagmatic and paradigmatic mixing of various kinds, and that cross-linguistically DAs often allow inbound attributive modification, that is, they show attributive transparency: in some languages precisely such constructions as *trusted friendless are possible.

\section{Relational adjectives as transpositions and as mixed categories}


Several of the examples of DAs we will be interested in are RAs. We follow Spencer (1999) in taking RAs to be essentially nouns-in-disguise with respect to their semantics, and therefore will restrict our use of this term to refer to a DA whose lexical semantic content is identical to that of the base noun lexeme. This characterization presupposes that we can identify differences of semantic content, although this proves somewhat elusive in some cases. For instance, many languages have a category of 'possessive adjective', but the semantics of possession is generally extremely vague. Nikolaeva and Spencer (2013) make the standard assumption that possession in this sense is a very general relation between a head noun and a dependent noun phrase or determiner phrase, while the standard interpretation of an RA is that of modification-by-noun, as in the case of an attributive endocentric noun-noun compound, that is, a very general relation between a head noun and a dependent noun.

We will argue that such semantically neutral RAs are of two broad kinds. In the first type the derived adjective is a distinct lexeme from the base noun lexeme, just as in the case of hopeless, friendless and so on. We will argue that this is true of English adjectives such as tidal from tide.

In its normal use, the derived adjective tidal does not add any lexical semantic content to its base noun tide, but simply means 'pertaining to the concept tide'. What this means is that whenever we have an expression of the form tidal $N$ (for a noun, $\mathrm{N}$ ) we will find a paraphrase of the form $N$ in/of/... the tide, or a compound tide $N$ with the same meaning. In other words, a sentence including tidal $N$ will have the same truth conditions (in nonopaque, de re contexts) as the same sentence with $N$ of... the tide or tide $N$ substituted. Thus, tidal measurements means measurements of the tide or tide measurements, tidal fluctuations means fluctuations in the tide and tidal barrier means tide barrier. An adjective like tidal contrasts in this regard with denominal adjectives such as fundamental (problem) or original (idea), which do not mean the same as 'pertaining to a/the fundament/origin'. ${ }^{4}$

Although the noun-to-adjective derivation does not appear to add any lexical semantic content here, the form tidal is not in any sense a member of the paradigm of the noun tide, and so it is not a true transposition. So if we call words such as tidal 'relational 
adjectives' that will mean that not all RAs are genuine transpositions, though they share with transpositions the property that they do not enrich the semantic content of the base noun lexeme while altering its morphosyntax. We will therefore distinguish genuine RAs (which are true transpositions) from derived lexemes such as tidal which behave semantically like RAs but which are distinct lexemes. Following Spencer (2013: 275, 360; see also Spencer 2016c) we will refer to this latter type of case as 'transpositional lexemes'. ${ }^{5}$

A major motivation for claiming that a RA such as tidal is not a true transposition will be the observation that such adjectives fail to give rise to syntagmatic mixing. In particular, these adjectives are attributively opaque: we do not find inbound attributive modification of the base lexeme TIDE, *high tidal currents (intended structure: [[high tide]al currents]). This contrasts with compounding: high tide currents is grammatical.

In Section 4 we will see examples of the attributively transparent RAs in Selkup and discuss how their behavior contrasts with classes of words labelled 'relational adjectives' in familiar European languages. In their second, purest, type RAs are true transpositions, that is, the adjectival forms or representations of nouns which exhibit syntagmatic (and in some cases also paradigmatic) mixing. One example discussed at great length by Corbett $(1987 ; 1995)$ is provided by Slavic possessive adjectives at various points in their history and especially by the Upper Sorbian possessive adjectives, in which the possessive suffix on the possessed noun behaves somewhat like the English possessive 's, in that it can take wide scope over an attributive modifier, a relative or personal pronoun (as though we could say in English my fraternal daughter for my brother's daughter).

The lack of attributive opacity is also typical of proprietive DAs, which are very regular and productive in Tungusic and a number of other Altaic languages (Nikolaeva 2014). ${ }^{6}$ Consider example (1) from the Southern Tungusic language, Udihe (Nikolaeva 2008):
(1) ic'a sita-xi a:nta
small child-PROP woman 
The word sita-xi is a proprietive adjective (with the meaning 'having a child'), modifying a:nta 'woman'. The proprietive adjective itself is derived from the noun 'child', root sita-. The DA sita-xi in (1) shows inbound attributive modification by the adjective ic'a 'small': [[ic'a sita]-xi a:nta].

Transpositional DAs can exhibit paradigmatic mixing. This is illustrated in example (2) from another Tungusic language, Evenki (Nikolaeva 2008).

(2)
aja-l
oro-l-či-du
asi:-du
good-PL reindeer-PL-PROP-DAT.SG
'to the woman with good reindeer (PL)'

woman-DAT.SG

[Evenki (Tungusic)]

In this example a proprietive adjective oro-l-čci-du is formed by suffixing the proprietive marker -či to the noun root oro- 'reindeer', (plural orol-), meaning 'having reindeer'. In (2) we can see that, with respect to the head noun $a s i$ - $d u$ 'woman', oro-l-čci-du is clearly an adjective: it is in prenominal position and it agrees in case with its head. On the other hand the nominal base of oro-l-či-du, oro-l, is modified itself by the adjective aja-l, which shows number agreement with the base noun. In other words, oro-l-či-du allows inbound attributive modification and thus exhibits attributive transparency. ${ }^{7}$

It is often reported that DAs are anaphoric islands (for instance, Alexiadou and Stavrou 2011). In part this is presumably because the nominal base is typically non-referential and denotes a non-determined concept (common noun denotation). For this reason the modifying noun may resist pronominal reference. Genitive case marked nouns often behave in a similar fashion, it seems (cf. Trugman 2004 for Russian; Cetnarowska 2014 for Polish) and modifier nouns in noun-noun compounds are generally non-referential: the cat in catfood does not refer to any particular cat or cats but rather to the kind 'cat'. Nonetheless, cross-linguistically we find a variety of constructions in which the transpositional DA seems to retain the referentiality of the base noun and permits outbound anaphora. This has also been reported for Tungusic proprietives (Nikolaeva 
2008). Thus, Udihe proprietive adjectives in $-x i$, illustrated in (1), are not anaphoric islands, as can be seen from (3) (Nikolaeva 2008: 976):

\begin{tabular}{|c|c|c|c|c|}
\hline (3) Uti & $\mathrm{zu}$ & ni: & xuńazi-xi & bi-si-ti \\
\hline That & two & man & elder.sister-PROP & be-PST-3PL \\
\hline Uti & 'ana-du & bi-si-ni & & \\
\hline that & boat-DAT & be-PST- & $S G$ & \\
\hline
\end{tabular}

'These two men had an elder sister.

She was in the boat.'

[Udihe (Tungusic)]

As was mentioned above, outbound anaphoric reference cannot be taken as the crucial evidence for true transpositions. The crucial type of syntagmatic mixing for us is inbound attributive modification. Udihe proprietives such as sita-xi 'having a child' are attributively transparent while in English DAs such as privative adjectives (friendless) or transpositional lexemes (tidal) are attributively opaque. Much of this paper will be an attempt to explicate this difference in behaviour. We will argue that the key to understanding the difference between English tidal and cases such as the Tungusic sita$x i, x u n ́ a z i-x i$ lies in the notion of 'lexeme'. English tidal is a transpositional lexeme and therefore it is a different lexeme from its base noun tide. Lexemic integrity demands that it behave like a simplex lexeme with respect to syntactic operations, such as attributive modification, and thus that it is attributively opaque. Tungusic proprietives, on the other hand, are, in a certain sense, a form of the base noun lexeme, even though morphologically they do not belong to the canonical nominal paradigm (unlike Selkup DAs discussed in the next section). It is for this reason that they exhibit attributive transparency: the proprietive form of the noun is transparent to modification in just the same way that, say, the plural of the noun is transparent to modification.

\section{Lexical representation}


We will illustrate our approach to these issues with the analysis of a single example from the South Samoyedic language, Selkup, taken from Helimskij (1998) (see Spencer 2013, Chapter Ten for a summary of Selkup grammar; we follow Helimskij's transcription here). In Selkup, nouns inflect for number, case and possession. Nouns also serve as the base for various categories of DA, notably proprietives ('having N') and privatives ('lacking N'). However, in addition there are three types of 'adjectival representation' of nouns (Kuznecova et al. 1980: 190-196; Spencer 2013: 397-398). The first is a pure RA, formed with the typical adjectival suffix $-l j$, which adds no semantic content to the denotation of the base noun. Thus, from alako 'boat' we have the RA alako-li, 'pertaining to a boat', as in alako-li lapi 'boat-oar'. However, the other two adjectival representations are more derivation-like in that they involve the addition of a semantic predicate to the lexical representation. These are the co-ordinative adjectival representation (actually, a kind of similitudinal adjective) in -šj(šj)alj, e.g. alako-ššs ${ }^{\prime} a l j$ 'similar to a boat', and the locative adjectival representation in -qïlj, e.g. alako-qïl '(located) on a boat'.

Following Spencer (2013), we treat Selkup co-ordinative and locative forms as meaning-bearing transpositions (adjectival representations of nouns) rather than common-or-garden derived forms. First, these DAs are morphologically part of the noun paradigm, because all three types can be formed from possessor-inflected forms of the noun, to give forms meaning 'pertaining to/similar to/located in my/your/their boat' etc. Moreover, all three transpositions are attributively transparent, as illustrated in (4) for RAs, where the word toljcï-lj 'skis' is a RA modified by the adjective po:-lj (itself a RA). Modifying adjectives always precede their head.

(4) po:-lj toljcï-lj mïtïn
wood-RA skis-RA grease
'grease for wooden skis'

Inbound attributive modification is also found with the possessor marked forms, as shown in (5) for the relational and the locational adjectival representations respectively of the noun 'boat' (Helimskij 1998: 562; the ko/koo stem allomorphy is regular): 


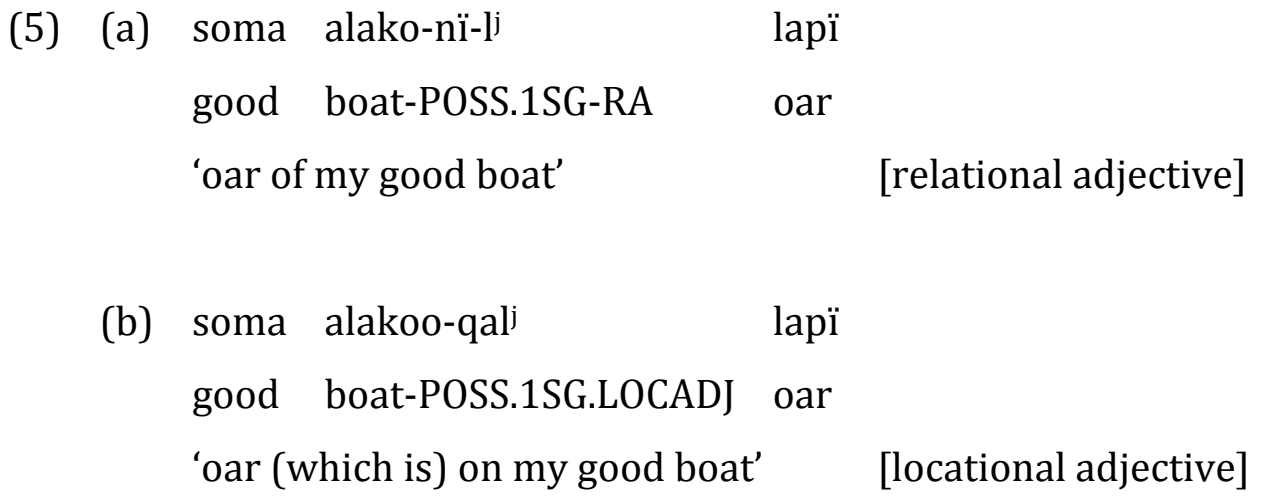

Notice that the LOCADJ suffix shows cumulation with the possessor agreement morphology: -qalj is a portmanteau form corresponding to the locative suffix -qïlj found with non-possessed nouns. (Interestingly, Helimskij indicates that the adjective soma 'good' in (5) can only modify 'boat' and not 'oar', cf. Kuznecova et al. 1980: 381-82).

Examples such as these represent a serious challenge to any model of grammar. We will analyse them in terms of the Generalized Paradigm Function Morphology (GPFM) approach to lexical relatedness developed in Spencer (2013). In the GPFM model a lexeme is an ordered tuple of attributes, including at least the following information: 〈FORM, SYN, SEM, LI〉. The FORM attribute specifies the non-predictable components of the phonological form of the lexeme. From this information the full inflectional paradigm can be deduced by applying the standard principles of morphology for the given language (for instance, as implemented by means of the paradigm function in Paradigm Function Morphology, Stump 2001). The SYNTAX (SYN) attribute provides at a minimum (i) a specification of the lexeme's morphosyntactic category; (ii) a specification of the lexeme's argument structure properties, and (iii) any additional collocational information (for instance, whether it takes a finite or non-finite complement). For the present we will assume the standard array of monovalent category labels N(oun), V(erb), A(djective), P(reposition), and possibly Adv(erb). The SEMANTICS (SEM) attribute we will take to be essentially a representation of Lexical Conceptual Structure in the manner of Jackendoff (1990), but considerably simplified, so that representations will in general consist of elements taken from a set of primitives such as CAUSE, BECOME, LOCATION-AT, SIMILAR-TO and so on, and a set of constants such as RUN, TREE, TALL. The fourth attribute, Lexemic Index (LI), is an arbitrary 
unique integer which individuates each separate lexeme. Paradigmatic lexical relatedness (as opposed to etymological, 'frozen', non-productive, accidental types of relatedness) are defined by a Generalized Paradigm Function or GPF (a generalization of the Paradigm Function of Stump 2001), which can change some or all of the values of the four attributes. Any application of the GPF which preserves the LI of the base is effectively defining a form of that base lexeme rather than defining a new lexeme (as would be found in the case of canonical derivational morphology, in which all four lexical attributes are changed non-trivially).

Of most interest to us here is the argument structure (A-STR) of the lexeme. It is commonly assumed that A-STR is defined over two sorts of argument. The thematic arguments are mapped to grammatical relations such as subject, object and so on. In addition, nouns are assumed to bear a role ' $\mathrm{R}$ ' (Williams 1981b): tree $\langle\mathrm{R}\rangle$, corresponding to $\lambda x$.tree(x). Verbs bear an eventuality role ' $E$ ' (Higginbotham 1985): hit $\langle\mathrm{E}\langle\mathrm{x}, \mathrm{y}\rangle\rangle$ (corresponding to $\lambda x, y[h i t(x, y)]$ or $\lambda e[h i t(e) \wedge \operatorname{Ag}(e) \wedge \operatorname{Pat}(e)])$.

Spencer $(1999,2013)$ refers to the additional R, E roles as 'semantic function roles' (sf roles) and proposes that the adjective category be furnished similarly with such a role. The canonical function of an adjective is to serve as an attributive modifier. ${ }^{8}$ Spencer argues that this is represented in the sf role of adjectives. The A-STR representation of a typical monovalent adjective such as Swedish: $\lambda \mathrm{x}[\operatorname{Swedish}(\mathrm{x})]$ therefore includes the sf role ' $A$ ': $\langle A\langle x\rangle\rangle$. Attributive modification can now be defined at the level of sf roles. The $A$ role is coindexed with the R role of the modified noun. Thus, for Swedish man, we have Swedish $\left\langle A^{x}\langle x\rangle\right\rangle \operatorname{man}\left\langle R^{x}\right\rangle$. The superscript ' $x$ ' notation is interpreted in this way: if the representation $\operatorname{man}\left\langle\mathrm{R}^{\mathrm{x}}\right\rangle$ corresponds to $\lambda \mathrm{x} \cdot \operatorname{man}(\mathrm{x})$, and $\mathbf{S w e d i s h}\langle\mathrm{A}\langle\mathrm{y}\rangle\rangle$ corresponds to $\lambda P . \lambda y[P(y) \wedge \operatorname{Swedish}(y)]$, then Swedish $\left\langle A^{x}\langle y\rangle\right\rangle \operatorname{man}\left\langle R^{x}\right\rangle$ corresponds to $[\lambda P . \lambda y[P(y) \wedge$ $\operatorname{Swedish}(y)]](\lambda x \cdot \operatorname{man}(\mathrm{x}))$, to give the standard representation for an intersective modifier, $\lambda x[\operatorname{man}(x) \wedge \operatorname{Swedish}(x)]$.

A major motivation for this modest enrichment of the A-STR representations is that it offers a model of transpositions. Spencer (2013: 139) provides strong empirical motivation for a Principle of Representational Independence (PRI) according to which the four principal lexical attributes can define relatedness between lexical 
representations (whether word forms, lexemes or intermediate types of representation) in a completely independent fashion, in other words sixteen distinct types of relatedness. Ignoring strict identity and the absurd case of two representations which have distinct LIs but are identical across all other attributes this leaves fourteen attested types of relatedness between (contextual) inflection and (canonical) derivation. The PRI thus induces a factorization of lexical relatedness, giving much finer-grained distinctions than the traditional inflection/derivation distinction.

First, consider the transpositional lexemes, illustrated by English tidal, prepositional, marine and similar cases in Russian and many other languages.

Spencer (1999) discusses the parallelism between noun-noun compounding (e.g. preposition phrase, telephone interview, sea life) and the modification of a noun by a RA (prepositional phrase, telephonic interview, marine life). The RAs prepositional, telephonic, marine have the same meaning as the nouns preposition, telephone, sea. The semantics of the typical endocentric (attributive) noun-noun compound construction is defined by a pragmatically interpreted relation $\mathfrak{R}$. This is the default semantics for all types of modification-by-noun construction and possessive constructions (Nikolaeva and Spencer 2013). Thus, preposition phrase means roughly 'phrase with some pragmatically determined relation to the concept of preposition', shown in (6):

$$
\exists \Re \exists x \cdot[\operatorname{phrase}(\mathrm{x}) \wedge \mathfrak{R}([\lambda y \cdot \operatorname{preposition}(\mathrm{y})], \mathrm{x})]
$$

This is also the semantic representation for prepositional phrase. On Spencer's (1999) account, the $\mathfrak{R}$ relation is introduced as a property of the noun-noun compounding construction, but it is also a lexical property of the RA.

RAs which are transpositional lexemes behave like a simplex adjective. We can represent this situation by assuming that the A-STR representation is, in fact, that of a simplex lexeme. Thus, although preposition and prepositional have exactly the same SEM representation, the A-STR of prepositional will be just $\langle A\langle\mathrm{x}\rangle\rangle$. 
Transpositional lexemes respect lexemic integrity: the base noun cannot be modified: *spatial prepositional phrase (cf. 'phrase head by a spatial preposition'), *high tidal currents and so on. The strongest assumption to make is that this is an automatic consequence of the fact that the LI of the base and RA are distinct, so prepositional bears a distinct LI from its base preposition. The simplest way of implementing that proposal would be to say that no form of lexical relatedness that modifies the base lexeme's LI can be associated with a composite sf role. That would then effectively erase the ' $R$ ' role from the RA and make it impossible for attributive modification to modify the noun denotation (even though the SEM representation is identical to that of the base noun). We leave this speculation for future research.

Returning now to true transpositions, in the model of word classes developed in Spencer $(1999,2013)$ transpositions differ from simplex categories in their sf roles: a transposition has a complex or composite sf role, in which the sf role of the derived category is added to that of the base to create an 'embedded' sf role complex. Thus, if the argument structure representation of a typical verb is $\langle E\langle x, \ldots\rangle\rangle$, where ' $\langle\mathrm{x}, \ldots\rangle$ ' is a string of thematic arguments, then an action nominal will have a complex sf role giving the A-STR representation $\langle\mathrm{R}\langle\mathrm{E}\langle\mathrm{x}, \ldots\rangle\rangle$, and a participle will have a complex sf role giving the A-STR $\langle\mathrm{A}\langle\mathrm{E}\langle\mathrm{x}, \ldots\rangle\rangle\rangle$.

The A-STR for RAs will thus have the complex sf role $\langle A\langle R\rangle\rangle$. Since an adjective is typically a one-place predicate the A-STR will also include a thematic argument position: $\langle A\langle x\rangle\langle R\rangle\rangle$. However, for readability we will generally suppress the ' $x$ ' argument.

On this account of the Selkup alako-lj lapi 'oar pertaining to a boat', the A-STR representation of alako-lj is $\langle\mathrm{A}\langle\mathrm{R}\rangle\rangle$ but the lexical semantics is identical to that of the noun boat, $\lambda x$.boat $(\mathrm{x})$. When used as an attributive modifier, the ' $\mathrm{A}$ ' role of alako-lj will be coindexed with the 'R' role of the head noun as we saw for Swedish man to give boat $\left\langle A^{x}\langle y\rangle\right\rangle \operatorname{oar}\left\langle R^{x}\right\rangle$. This licenses the elaborated semantic representation corresponding to an attributive modifier, as shown in (7): $\exists \Re \lambda P \lambda x \cdot[\mathrm{P}(\mathrm{x}) \wedge \Re([\lambda y \cdot \operatorname{boat}(\mathrm{y})], \mathrm{x})]$ 
In paradigm-based models of morphology, including GPFM, inflected forms are defined in terms of features, and this is no different for transpositions. The GPF for Selkup defines transpositions by means of the quasi-inflectional feature REPRESENTATION (REPR), following Smirnickij 1959 and Haspelmath 1996 (see also Kuznecova et al. 1980; Helimskij 1998: 557). The six major types of transposition can therefore conveniently be labelled as [REPR: $\{\mathrm{V} 2 \mathrm{~N}, \mathrm{~A} 2 \mathrm{~N}, \mathrm{~A} 2 \mathrm{~V}, \mathrm{~N} 2 \mathrm{~V}, \mathrm{~V} 2 \mathrm{~A}, \mathrm{~N} 2 \mathrm{~A}\}]$, where the mnemonic feature names V2N and so on are to be interpreted as 'verb-to-noun (transposition)'. For transpositional RAs, if $\mathrm{LI}_{\mathrm{n}}$ is the Lexemic Index of the base noun, the GPF will map the pairing $\left\langle\mathrm{LI}_{n},\{\mathrm{REPR}: \mathrm{N} 2 A\}\right\rangle$ to the lexical representation of the transposed word. ${ }^{9}$ In this sense such RAs are not autonomous lexemes and this is the analysis we will adopt for those RAs that are true transpositions.

Recall, however, that lexical relatedness respects the Principle of Representational Independence, under which related lexical items can vary freely among all four principal dimensions of representation. This freedom applies to the SEM attribute, which determines whether two lexical items have identical, unrelated, or overlapping lexical semantic content. Thus, by the PRI we expect to see cases of (non-canonical) inflectional morphology which introduce semantic content into the SEM representation of a lexeme, even though, as inflection, that morphology does not define a distinct lexeme. Conversely, we expect to see cases of (non-canonical) derivational morphology which leave the SEM representation of the base word unchanged (transpositional lexeme). Now, a true transposition is a form ('representation') of the base lexeme, not a distinct lexeme, so we do not expect it to alter the SEM attribute of the base. But the PRI predicts that we should also see cases of (non-canonical) transpositions, 'meaningbearing transpositions', which add content to the base lexeme's SEM attribute just like some types of inherent inflection). This is precisely what we saw with the co-ordinative and locative adjectival representations in Selkup. As mentioned above, such DAs in Selkup are different from the RAs in that they introduce their own semantic contribution. For this reason their semantics does not include the pragmatically determined $\mathfrak{R}$ relation. 


\section{Syntax and semantics}

We now turn to the syntactic representation of DAs. We will adopt the LFG framework, which distinguishes the phrase structure representation (c-structure) from an independent level of representation (projection) defining the grammatical relations realized by c-structure nodes, f-structure. LFG also admits a level of argument structure (a-structure). In Spencer (2013, 2016a,b) an LFG implementation of the lexical A-STR representations and the sf roles is proposed. The basic morphosyntactic category of a major class lexeme is automatically derivable from the argument structure representation.

A central feature of that analysis is the possibility of defining a function, $\alpha_{c}$ directly from a-structure representations to c-structure nodes. This is a built-in design feature of lexical models such as LFG (or HPSG). The $\alpha_{c}$ function when applied to the simplex roles R, E, A will map the representation to N, V, A nodes (or projections thereof). When applied to the composite sf roles it maps the A-STR representation to a c-structure node which has no traditional label and which corresponds to a mixed category.

Consider again the examples of inbound attributive modification in (5) shown schematically in (8):

$$
\text { [AP [AP good] [a boat-LOCADJ] (oar)] }
$$

Here we see an adjective unexpectedly in construction with another adjective. The simplest way of coding this fact is just to write it into the language's phrase structure syntax: AP $\Rightarrow$ AP A. In the case of an ordinary adjective such as 'tall', say, such modification is not possible, of course: * good tall makes no sense unless both adjectives independently modify some (unstated) noun. What excludes modification of an ordinary adjective by another adjective is the fact that the attributive modifier is constrained to modify a lexeme which has a nominal denotation. We can ensure this by appeal to the A-STR representations enriched with composite sf roles. This means that we need to ensure that an attribute with sf role $\mathrm{A}$ is able to co-index its A role with the embedded $\mathrm{R}$ role in the representation of the RA, (9): 
(9)
a.
$\left\langle\mathrm{A}^{\mathrm{y}}\left\langle\mathrm{R}_{\mathrm{x}}\right\rangle\right\rangle$
$\left\langle\mathrm{R}_{\mathrm{y}}\right\rangle$
boat.LOCADJ
oar
'(oar which is) in a boat'
b. $\quad\left\langle\mathrm{A}^{\mathrm{x}}\right\rangle$
$\left\langle\mathrm{A} y\left\langle\mathrm{R}_{\mathrm{x}}\right\rangle\right\rangle$
$\left\langle\mathrm{R}_{\mathrm{y}}\right\rangle$
good
boat.LOCADJ
(oar)
'(oar which is) in a good boat'

Although the RA is of the 'wrong' category to be modified by an adjective, the adjective needs to have access to the nominal property of the base lexeme and needs to be able to modify the adjectival representation despite the non-canonical c-structure.

The proposed c-structure for our Selkup example can be represented schematically as in Figure 1.

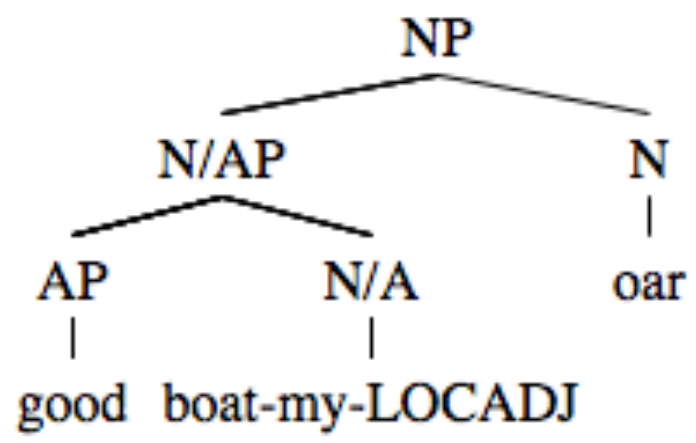

Figure 1. Proposed phrase structure for ( $5 \mathrm{~b})$

In Figure 1 we have put the adjective good in construction with the locational adjectival representation in my boat, because good can only modify boat and not oar (see above).

The notation 'N/A(P)' is used to label a c-structure node that has a complex sf astructure correspondent. However, given the sf notation, and the $\alpha_{c}$ correspondence function, it is very important to bear in mind that these labels are mere conventions, and in some respects misleading, as no new mixed type of phrasal category is being created. The adjective 'good' is the c-structure correspondent of a word with (simplex) 
sf role A, and 'oar' is the c-structure correspondent of a word with sf role R, but the astructure correspondent of the N/A(P) projection is a transpositional form, with the complex $\operatorname{sf}\langle A\langle R\rangle\rangle$, whose A component permits the phrase it heads to be an attributive (adjectival) modifier of 'oar', and whose R component permits it to be modified itself by an adjective. The simplest assumption to make is that such inbound modification is possible only when the DA is a true transposition, and hence still in some sense a form (better, representation) of the base noun lexeme. This is also the strongest assumption and may well prove to be too strong, but it is a useful starting point for wider investigation of RAs. An even stronger claim is the biconditional: inbound modification is possible iff the RA is a noun-to-adjective transposition, equivalently, iff the LI of the base and derived word are identical.

To be explicit about the way the embedded noun is modified we can finally propose an LFG f-structure, derived by the simultaneous satisfaction of a-structure, c-structure and lexical representations, together with the standard mapping from c-structure to $\mathrm{f}$ structure, the a-structure to c-structure mapping, and a mapping from a-structure to fstructure. The resulting f-structure will be roughly that shown in (10).

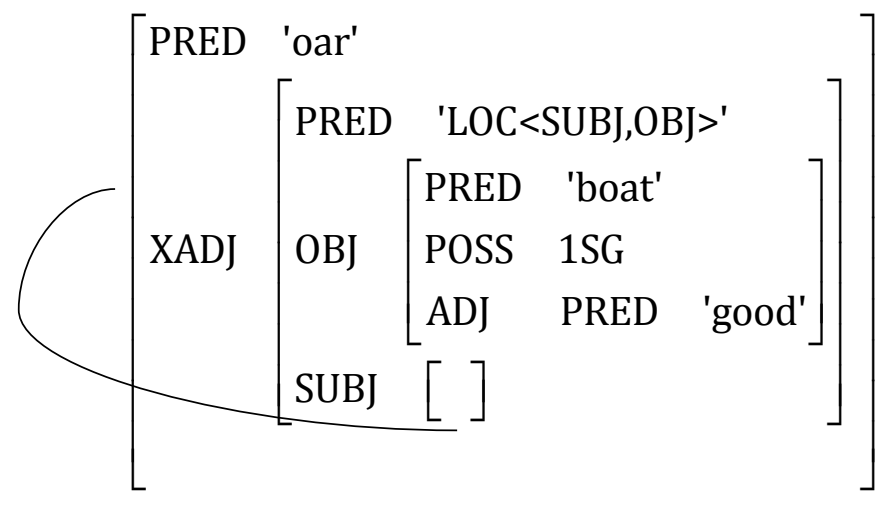

Here we follow the approach of Haug and Nikitina (2012) in treating the adjective as an open adjunct with a SUBJ attribute which is then coindexed with the f-structure of the head noun. By modifying various technical details of this analysis we could, we believe, implement it using the HPSG model of Ackerman and Nikolaeva (2013). Space considerations make that impracticable so we leave that possibility for future research too. 
We also need to define the semantics of the DA construction. A reviewer has suggested a promising analysis, making use of the proposal of McNally and Boleda (2004) under which RAs are treated like normal adjectives except that they modify kinds rather than objects. The denotation of a common noun is then taken to be a kind which is realized as an object by virtue of the realization function R (Carlson 1977):

$\lambda \mathrm{x}_{\mathrm{k}} \lambda \mathrm{y}_{\mathrm{o}}\left[\mathrm{R}\left(\mathrm{y}_{\mathrm{o}}, \mathrm{x}_{\mathrm{k}}\right) \wedge \mathrm{N}\left(\mathrm{x}_{\mathrm{k}}\right)\right]$ where $\mathrm{x}_{\mathrm{k}}$ denotes an entity of sort 'kind' and $\mathrm{y}_{\mathrm{o}}$ denotes an entity of sort 'object'

The virtue of this ontological enrichment is that the RAs can then be treated as semantic modifiers on a par with other adjectives. ${ }^{10}$

The reviewer then suggests an analysis of the Selkup examples based on the analysis of 'ethnic adjectives' proposed in Arsenijević et al. (2014). We assume that the adjective prepositional, when in an attributive modification construction, has the representation (12), a slightly modified variant of (6).

$$
\exists \mathfrak{R} \lambda \mathrm{P}\left[\mathrm{P}\left(\mathrm{x}_{\mathrm{k}}\right) \wedge \mathfrak{R}\left(\lambda \mathrm{u}_{\mathrm{k}}\left[\text { preposition }\left(\mathrm{u}_{\mathrm{k}}\right)\right], \mathrm{x}_{\mathrm{k}}\right)\right]
$$

The expression prepositional phrase on this analysis will therefore have the representation shown in (13).

\section{$\exists \mathfrak{R}\left[\operatorname{phrase}\left(\mathrm{x}_{\mathrm{k}}\right) \wedge \mathfrak{R}\left(\lambda \mathrm{u}_{\mathrm{k}}\left[\operatorname{preposition}\left(\mathrm{u}_{\mathrm{k}}\right)\right], \mathrm{x}_{\mathrm{k}}\right)\right]$}

Applied to the Selkup locational adjectives, this analysis would work approximately as shown in (14) (where IN(x,y) is a representation of the inessive case and POSS(1SG,y) represents whatever 'my $\mathrm{N}_{\mathrm{y}}$ ' means).

(14) (a) $\quad[$ boat-LOCADJ] $=\lambda y \lambda x \cdot[\operatorname{IN}(x, y)) \wedge P O S S(1 S G, y) \wedge$ boat $(y)]$

(b) $[[\operatorname{good}$ boat-LOCADJ] $]=\lambda y \lambda x[\operatorname{IN}(\mathrm{x}, \mathrm{y})) \wedge \mathrm{POSS}(1 \mathrm{SG}, \mathrm{y}) \wedge \operatorname{boat}(\mathrm{y}) \wedge \operatorname{good}(\mathrm{y})]$ 
(c) $[$ [good boat-LOCADJ oar] $]=\lambda x \exists y \cdot[\operatorname{IN}(\mathrm{x}, \mathrm{y})) \wedge \operatorname{POSS}(1 \mathrm{SG}, \mathrm{y}) \wedge \operatorname{boat}(\mathrm{y}) \wedge$ $\operatorname{good}(\mathrm{y}) \wedge \operatorname{oar}(\mathrm{x})]$

Similar representations can be deployed for the other two representational adjectives, with the IN predicate replaced by the $\mathfrak{R}$ relation for RAs and a SIM predicate expressing similarity for the co-ordinative adjectives.

Under this analysis the semantic representation of the locative adjectival form of 'boat' will be essentially identical to that of the inessive case of the noun 'boat'. The main difference between the two forms seems to be syntactic: the locative adjectival representation is a specific form for expressing attributive modification, while the locative case form of the noun is first and foremost an adverbial form. As far as we can tell, with the exception of the genitive, of course, case-marked nouns on their own are unable to function as attributive modifiers in Selkup. We have found no unequivocal examples of such NP-internal modification by oblique case marked NPs in the survey of case usage in Bekker (1976). In this respect Selkup resembles Tundra Nenets, another Samoyedic language (Nikolaeva 2014: 168), as well as Hungarian (Kenesei et al. 1998: 97-98).11

\section{Conclusions and prospects}

We have argued that some languages permit a regular noun-to-adjective transposition giving rise to paradigmatically and syntagmatically mixed denominal adjectives. Adjectival representations of nouns in languages such as Selkup function as forms of the base noun lexeme. This accounts for why they exhibit inbound attributive modification, in which the base noun is modified even though it is a proper subpart of an adjective: in a certain sense these adjectives remain nouns, both syntactically and morphologically and it is this property which permits them to be attributively transparent. They therefore differ crucially from the RAs of more familiar European languages, such as English tidal or prepositional, which are attributively opaque, that is, they do not violate 
lexemic integrity. These are transpositional lexemes, a genuine instance of derivational morphology which happens not to introduce any additional semantic content to the derived lexeme and which therefore partially fulfills the function of the true transposition. The contrast between true transpositional RAs and the transpositional lexemes provides strong motivation for the notion of a Lexemic Index serving to individuate lexemes.

Our research raises a number of questions for future exploration. The degree to which adjectival representations of nouns are mixed, whether syntagmatically or paradigmatically, depends on language-specific factors which are still poorly understood for transpositions generally. From the morphological perspective, paradigmatically mixed categories raise two, independent, questions: to what extent does the mixed category acquire properties of the derived word class? to what extent does the mixed category lose properties of the base word class? The question has been asked for action nominals in a detailed typological study by Malchukov $(2004,2005$, 2006), and for participial relative clauses, that is, verb-to-adjective transpositions, this has been investigated by Lehmann $(1984,1986)$, while Lowe $(2015)$ provides a detailed study of the expression of verbal tense properties in Sanskrit participles. So the general picture with transpositions from verb to noun/adjective is rather clear. There is a tendency for the most verb-related properties, such as voice alternations, to be retained in the transposition (in accordance with the Relevance Hierarchy of Bybee 1985). There is also a tendency for the least verb-related properties, such as mood or subject agreement, to be lost. Conversely, there is a tendency for the least noun/adjective related properties, such as concord, to be acquired, while the more noun/adjective related properties, such as nominal number or comparison of adjectives, tend not to be acquired. But while these are strong tendencies it is difficult to turn them into unexceptional universals, even of the implicational kind.

It should not be surprising, therefore, that we have seen a certain amount of variation in the acquisition of adjectival properties and the loss of noun properties in the very limited data from DAs we have presented here. In particular, we find that in some Tungusic languages the DA is likely to retain the noun's number property, but not the 
less noun-related property of possessor agreement, while in Selkup exactly the opposite pattern is seen. This must remain a topic for future research.

A further important question concerns the nature of the violations of lexical integrity shown by the DAs. We have only discussed one, admittedly important, syntactic property of the base noun, the ability to take attributive modifiers, but nouns enter into other syntactic configurations. For instance, it would be important to determine to what extent a genuine noun-to-adjective transposition (as opposed to the transpositional lexemes of familiar European languages) could express grammatical relations of the kind implied by deverbal nominalizations. For instance, in English we can say things like cervical manipulation, foetal repositioning (by the doctor), where the adjectives cervical and foetal seem to denote direct objects (cervical vertebra, foetus), but in general DAs cannot bear grammatical functions in English (whether they are so-called 'ethnic adjectives' or some other type, Koshiishi 2011). However, even for well-studied and well-documented languages there is, in fact, a dearth of reliable data on which to base a firm conclusion, and for less well-known languages the question has yet to be asked systematically. 


\section{Abbreviations}

A - adjective, Adv - Adverb, AP - Adjective Phrase, A-STR - argument structure, DA denominal adjective, DAT - dative, F - feminine, GEN - genitive, GPF - generalized paradigm function, GPFM - Generalized Paradigm Function Morphology, HPSG - Headdriven Phrase Structure Grammar, LFG - Lexical Functional Grammar, LI - Lexemic Index, LOC - locative case, LOCADJ - locational adjective, MORCLASS MORPHOLOGICAL CLASS (feature), MORSIG - MORPHOLOGICAL SIGNATURE (feature), N - noun, NOM - nominative, NP - Noun Phrase, PL - plural, POSS - possessive, PRI Principle of Representational Independence, PROP - proprietive (adjective) , PST -past, RA - relational adjective, REPR - REPRESENTATION (feature), SEM - SEMANTICS (attribute), sf - semantic function (role), SG - singular, SIMADJ - similitudinal adjective, SUBJ - subject, SYN - SYNTAX (attribute), V - verb 


\section{References}

Ackerman, Farrel and Irina Nikolaeva 2013. Descriptive typology and linguistics theory: a study in the morphosyntax of relative clauses. Stanford: CSLI.

Alexiadou, Artemis 2010a. Nominalizations: a probe into the architecture of grammar. Part I: the nominalization puzzle. Language and Linguistics Compass 4: 496-511.

Alexiadou, Artemis 2010b. Nominalizations: a probe into the architecture of grammar. Part II: the aspectual properties of nominalizations, and the lexicon vs. syntax debate. Language and Linguistics Compass 4: 512-523.

Alexiadou, Artemis and Melita Stavrou 2011. Ethnic adjectives as pseudoadjectives. Studia Linguistica 6: 1-30.

Arsenijevic, Boban, Gemma Boleda, Berit Gehrke and Louise McNally 2014. Ethnic adjectives are proper adjectives. In Rebekah Baglini, Timothy Grinsell, Jonathan Keane, Adam Roth Singerman \& Julia Thomas (eds.) Proceedings of the 46th Annual Meeting of the Chicago Linguistic Society. Chicago, IL: Chicago Linguistic Society. 17- 30.

Bekker, Erika Genrixovna 1978. Kategorija padeža v sel'kupskom jazyke. [On the category of case in Selkup]. Tomsk: Izdatel'stvo TGU.

Booij, Geert 1996. Inherent versus contextual inflection and the split morphology hypothesis. In Geert Booij and Jaap van Marle (eds.) Yearbook of Morphology 1995. Dordrecht: Kluwer. 1-16.

Bybee, Joan L. 1985. Morphology: a Study of the relation between meaning and form. Amsterdam: John Benjamins.

Carlson, Gary N. 1977. Reference to kinds in English. Unpublished University of Massachusetts PhD dissertation, Amherst.

Cetnarowska, Bożena 2014. On the (lack of) referentiality of Polish relational adjectives. In Ludmila Veselovská \& Markéta Janebová (eds.) Complex visibles out there. Proceedings of the Olomouc Linguistics Colloquium 2014: Language use and linguistic structure, Olomouc: Palacký University. 349-368.

Comrie, Bernard and Sandra A. Thompson 2007. Lexical nominalization. In Timothy Shopen (ed.) Language typology and syntactic description. Volume III: Grammatical Categories and the Lexicon. Cambridge: Cambridge University Press. 334-381.

Corbett, Greville G. 1987. The morphology-syntax interface. Language 63: 299-345. 
Corbett, Greville G. 1995. Slavonic's closest approach to suffix copying: the possessive adjective. In Frans Plank (ed.) Double Case: Agreement by Suffixaufnahme. Oxford: Oxford University Press. 265-282.

Dalrymple, Mary 2001. Lexical Functional Grammar. Orlando: Academic Press.

Haspelmath, Martin 1996. Word-class-changing inflection and morphological theory. In Geert Booij \& Jaap van Marle (eds.) Yearbook of Morphology 1995, Dordrecht: Kluwer Academic Publishers. 43-66.

Haug, Dag \& Tanya Nikitina 2012. The many cases of non-finite subjects: The challenge of "dominant" participles. In: Butt. M. and King, T. (eds.) Proceedings of the LFG12 Conference.

http://web.stanford.edu/group/cslipublications/cslipublications/LFG/17/lfg12.pdf

Higginbotham, James 1985. On semantics. Linguistic Inquiry 16: 547-621.

Helimskij, Evgenij 1998. Selkup. In Daniel Abondolo (ed.) The Uralic languages. London: Routledge. 548-579.

Jackendoff, Ray S. 1990. Semantic structures. Cambridge, Massachusetts: MIT Press. Kenesei, István, Robert M. Vágo \& Anna Fenyvesi 1998. Hungarian. London: Routledge. Koshiishi, Tetsuya 2011. Collateral adjectives and related issues. Bern: Peter Lang Verlag. Kuznecova, Ariadna Ivanovna, Evgenij Arnol'dovič Xelimskij \& Elena Vladislavovna Gruškina 1980. Očerki po sel'kupskomu jazyku [Studies in Selkup]. Moscow: Izdatel'stvo Moskovskogo Universiteta.

Lehmann, Christian 1984. Der Relativsatz. Tübingen: Gunter Narr Verlag. Lehmann, Christian 1986. On the typology of relative clauses. Linguistics 24: 663-680. Lieber, Rochelle 2004. Morphology and Lexical Semantics. Cambridge: Cambridge University Press.

Lieber, Rochelle 2015. The semantics of transposition. Morphology 25: 353-369.

Lowe, John 2015. Participles in Rigvedic Sanskrit: The Syntax and Semantics of Adjectival Verb Forms. Oxford: Oxford University Press.

Malchukov, Andrei 2004. Nominalization/verbalizations: constraining a typology of transcategorial operations. Munich: LINCOM Europa.

Malchukov, Andrei 2005. Remarks on deverbalization. Sprachtypologie und Universalienforschung 58: 97-110. 
Malchukov, Andrei 2006. Constraining nominalization: function-form competition. Linguistics 44-45: 973-1008.

McNally, Louise \& Gemma Boleda 2004. Relational adjectives as properties of kinds. In Olivier Bonami \& Patricia Cabredo Hofherr. (eds.), Empirical Issues in Syntax and Semantics 5: 179-196.

Nikolaeva, Irina. 2008. Between nouns and adjectives: a constructional view. Lingua 118 (7): 969-996.

Nikolaeva, Irina 2014. Altaic. In: Rochelle Lieber \& Pavol Štekauer (eds.) The Oxford handbook of derivational morphology. Oxford University Press. 493-508.

Nikolaeva, Irina \& Andrew Spencer 2013. Possession and modification - a perspective from Canonical Typology. In Dunstan Brown, Marina Chumakina \& Greville Corbett (eds.) Canonical Morphology and Syntax. Oxford: Oxford University Press. 207-238

Postal, Paul M. 1969. Anaphoric islands. Chicago Linguistic Society 5: 205-239.

Schachter, Paul \& Timothy Shopen. 2007. Parts-of-speech systems. In Timothy Shopen (ed.) Language typology and syntactic description. Vol. 1, Clause structure. Cambridge: Cambridge University Press. 1-60.

Smirnitskij, Aleksandr Ivanovich 1959. Morfologija anglijskogo jazyka. [English morphology]. Moscow: Nauka.

Spencer, Andrew 1999. Transpositions and argument structure. In Geert Booij \& Jaap van Marle (eds.) Yearbook of Morphology 1998. Dordrecht: Kluwer. 73-102.

Spencer, Andrew 2005. Towards a typology of 'mixed categories'. In Orhan Orgun \& Peter Sells (eds.) Morphology and the web of grammar. Essays in memory of Steven G. Lapointe. Stanford University: Center for the Study of Language and Information. 95-138.

Spencer, Andrew 2013. Lexical Relatedness: a Paradigm-based model. Oxford: Oxford University Press.

Spencer, Andrew 2016a. Individuating lexemes. In Miriam Butt and Tracy Holloway King (eds) Proceedings of LFG15, pages 357-377. Stanford: CSLI Publications, http://csli-publications.stanford.edu/

Spencer, Andrew 2016b. Participial relatives in LFG. In Miriam Butt and Tracy Holloway King (eds) Proceedings of LFG15, pages 378-398. Stanford: CSLI Publications, http://csli-publications.stanford.edu/ 
Spencer, Andrew 2016c. How are words related? In Daniel Siddiqi and Heidi Harley (eds). Morphological Metatheory, pages 1-26. Amsterdam: John Benjamins Publishing Co.

Stump, Gregory 2001. Inflectional morphology. Cambridge: Cambridge University Press. Trugman, Helen 2004. Syntax of Russian DPs, and DP-internal agreement phenomena. Unpublished PhD dissertation, Tel Aviv University.

Ward, Gregory, Richard Sproat, R \& Gail McKoon 1991. A pragmatic analysis of socalled anaphoric islands. Language 67: 439-474.

Williams, Edwin 1981a. On the notions 'lexically related' and 'head of a word', Linguistic Inquiry 12: 245-274.

Williams, Edwin 1981b. Argument structure and morphology. The Linguistic Review 1: 18-114.

\footnotetext{
${ }^{1}$ We have presented some of this material at the September 2014 meeting of the Linguistics Association of Great Britain, The Queen's College, Oxford. We are grateful to the editors and to an anonymous reviewer for detailed criticism which helped us improve an earlier draft.
}

${ }^{2}$ Spencer (2103) abundantly illustrates the need for the category of transposition in understanding lexical relatedness cross-linguistically and the reader is referred to that discussion for further arguments.

${ }^{3}$ Lexical drift will often create new lexemes from transpositions, of course, but that is an independent phenomenon.

${ }^{4}$ As Lieber (2015: 368) shows, RAs in English often undergo semantic drift and become qualitative adjectives. This may even be true of tidal in an expression such as tidal wave. However, we are focussing on the purely relational uses, in which the RA is effectively a noun-in-disguise functioning as an attributive modifier. Lieber does not actually address those usages in her article.

${ }^{5}$ Lieber (2015) argues that genuine transpositions will be comparatively rare and that English, in particular largely lacks transpositions. The examples she discusses are all 
instances of transpositional lexemes, (including, pace Spencer, 2013, property nominalizations such as kindness, sincerity, which we would now take to be transpositional lexemes), so to that extent we concur. However, she bases her conclusions on the theoretical framework of Lieber (2004), arguing that it is a prediction of that framework that transpositions will be rare cross-linguistically. Our impression is different: even English, with its minimal morphology, has true transpositions, one of which, the POSS-ACC -ing nominalization illustrated earlier, shows syntagmatic mixing. Participial relative clauses in -ing, as in anyone [definitely knowing the answer] likewise are transpositions. Lieber does not actually discuss any of the transpositions argued for in Spencer (2013) such as those of Selkup, and it is not clear to us how her framework would handle them.

${ }^{6}$ One way of interpreting proprietives is as meaning-bearing transpositions, since they are typically glossed as though they introduced the predicate 'having(N)' (e.g. bearded man = man having beard . Alternatively, they can be viewed as falling within a very large semantic range denoting possession, if the latter is understood fairly loosely as a certain (pragmatically and/or lexically defined) association between two entities, and therefore as some sort of RAs.

7 We are not aware of any systematic study of the range of nominal morphosyntactic properties that can be retained in DAs. But we will see another important example of paradigmatic mixing in Section 4 when we come to look at DAs in the Samoyedic language, Selkup.

${ }^{8}$ Adjectives are often used predicatively, of course, but this is true of nouns (Harriet is a doctor) and even prepositions (The doctor is in/in the surgery), so clearly the predicative function is secondary.

9 The DA inflects as an adjective, and not as a noun, so the GPF must also redefine the inflectional paradigm of the transposition so that it is that of an adjective. In the GPFM model this is achieved by overwriting the 'morphological signature', MORSIG, of the lexeme. This attribute defines the set of properties (nominal, verbal, adjectival) that the lexeme inflects for and assigns it to a morpholexical class (MORCLASS, a value of 
MORSIG). The GPF applied to the $\langle\mathrm{N},\{$ REPR:N2A\} $\rangle$ pairing redefines the MORSIG attribute as part of its operation and defines which MORCLASS the transposition belongs to.

${ }^{10}$ We leave for future research the question of how the kind/object distinction works in cases of modification-by-noun, for instance, noun-noun compounding.

11 The reviewer suggests that the semantic analysis just presented renders the A-STR based account (9) superfluous. However, this is an error: the semantic analysis correctly allows us to express the fact that prepositional phrase means exactly the same as preposition phrase (and similarly for other languages with several ways of expressing modification-by-noun), but our A-STR account is needed to allow us to distinguish noun-noun compounding from modification by an adjective. 